\title{
p53 mutation in histologically normal mucosa of the aero-digestive tract is not a marker of increased risk for second primary carcinoma in head and neck cancer patients
}

\author{
Anette Escher $\cdot$ Elsa Piotet $\cdot$ Francois Waridel $\cdot$ \\ Richard Iggo $\cdot$ Philippe Monnier
}

Received: 7 January 2008 / Accepted: 21 July 2008 / Published online: 8 August 2008

(C) Springer-Verlag 2008

\begin{abstract}
Head and neck cancer patients are at high risk for developing second primary tumors. This is known as field cancerization of the aero-digestive tract. In a previous study, we showed that patients with multiple primary tumors were more likely to have p53 mutations in histologically normal mucosae than patients presenting with an isolated tumor. Based on this observation, we postulated that p53 mutations in normal tissue samples of patients bearing a single primary tumor could have a clinical value as a biomarker for the risk of developing second primary tumors. Thirty-five patients presenting with a single primary tumor were followed-up for a median of 51 months (range 1 month to 10.9 years) after biopsies of histologically normal squamous cell mucosa had been analyzed for p53 mutations with a yeast functional assay at the time of the primary tumor. During this follow-up, recurrences and non-sterilization of the primary tumor, occurrence of lymph node metastases, and of second primary tumors were evaluated. Sixteen $(45.7 \%)$ patients were found to have p53 mutations in their normal squamous cell mucosa, and 19 (54.3\%) patients showed no mutation. No relationship was found between p53 mutations and the occurrence of evaluated events during follow-up. Notably, the rate of second primary tumors was not associated with p53 mutations in the normal squamous mucosa. The correlation between p53 mutations in histologically normal mucosae and the
\end{abstract}

A. Escher $(\varangle) \cdot$ E. Piotet · F. Waridel $~ \cdot$ P. Monnier Department of Otolaryngology and Head and Neck Surgery, University Hospital, Centre Universitaire Hospitalier Vaudois (CHUV), rue du Bugnon 46, 1011 Lausanne, Switzerland e-mail: anette.escher@chuv.ch

\section{R. Iggo}

Bute Medical School, University of St Andrews, KY169TS, St Andrews, UK incidence of second primary tumors is generally low. The benefit of analyzing p53 mutations in samples of normal squamous cell mucosa in every patient with a primary tumor of the head and neck is doubtful.

Keywords Head and neck cancer .

Second primary tumor $\cdot$ p53 $\cdot$ Field cancerization

\section{Introduction}

Squamous cell carcinoma of the head and neck (SCCHN) is a very common malignancy and has one of the lowest 5year survival rates among all cancers [1]. Although new surgical techniques, improved radiotherapy regimens and use of concomitant chemotherapy all improve loco-regional control, improvement of survival has not been achieved over the last decades [2]. One of the main reasons for this lack of efficacy seems to be that, apart from failure of locoregional disease control, head and neck cancer patients are at high risk of developing second primary tumors (SPT), regardless of initial treatment modality [3]. This high incidence of SPT reflects the so-called field cancerization process of the aero-digestive tract, in which the epithelium has been preconditioned by long-term exposure to carcinogens [4]. Multifocal disease has been seen in 3-7\% of the cases worldwide [5], and some specialized centers report up to $24 \%$ of patients developing metachronous second primary tumors [6]. One of the major molecular mechanisms of tumor development lies in multiple mutations in oncogenes and tumor suppressor genes [7]. Mutation of the tumor suppressor gene p53 is one of the most frequent and it occurs in about half of all types of tumors [8].

Ten years ago (during the years 1995-1996) we analyzed multiple biopsies of squamous cell carcinomas and 
of histologically normal mucosae in 36 patients bearing a single primary tumor and 16 patients presenting with multiple synchronous primary tumors. Several biopsies from the mucosa of the upper aero-digestive tract were taken from every patient of each group, 117 biopsies from the 36 patients with a primary single tumor and 50 biopsies from the 16 patients with multiple tumors. A yeast p53 functional assay, a biological assay for transactivation of a reporter gene in yeast was done on each biopsy specimen. The ability to activate transcription of target genes is a critical activity of p53, which is targeted in tumors. In most cases, failure to activate transcription in tumors results from mutations in the p53 DNA binding domain, which lower the affinity of p53 for DNA. By testing the biologically important function of the protein, it is possible to distinguish polymorphisms from tumorigenic mutations, and to identify mutations at many different sites in a single assay [9]. Using this method, mutations were detected in 46 of 53 (87\%) tumors. Among the biopsies of histologically normal mucosae taken from the upper aerodigestive tract, p53 mutations were identified in 38 of 50 (76\%) biopsies from patients presenting with multiple tumors, compared with 38 of 117 (32\%) biopsies from patients presenting with a single tumor $(P<0.000001)$. All 16 patients presenting with multiple tumors had at least one positive biopsy, compared with only 19 of 36 $(53 \%)$ patients with single tumors $(P<0.001)$ [10]. These results confirmed that inactivation of the p53 tumor suppressor gene is a frequent and early event in the pathogenesis of head and neck tumors. Furthermore, expansion of multiple clones of mutant p53-containing cells was found to be an important biological mechanism of field cancerization. Since patients with multiple primary tumors were significantly more likely to show p53 mutations in normal squamous cell mucosa, compared to patients bearing a single tumor, it was postulated that p53 mutations in normal squamous cell mucosa could represent a molecular marker of multifocality $[9,10]$. As $25 \%$ of the patients presenting with a single tumor are expected to develop additional tumors [6], follow-up of these patients is of great interest, especially if detection of p53 mutations in adjacent normal squamous mucosa permits to predict a multifocal pattern of disease. A systematic analysis of p53 mutations in histologically normal tumor-distant mucosae ( $\geq 5 \mathrm{~cm}$ from the primary) would thus facilitate identification of those patients most likely to benefit from intensive follow-up for the detection of metachronous second primary tumors.

Here, we present the results of the long-term follow-up of the above-mentioned 36 patients presenting with a single primary tumor, who, 10 years ago, had been tested for $\mathrm{p} 53$ mutations in their histologically normal squamous cell mucosae.

\section{Patients and methods}

Approval for the study was obtained from the local ethical committee (protocol F63/94) and informed consent was obtained from all persons prior to inclusion. From October 1995 to July 1996, 36 unselected patients underwent diagnostic broncho-esophagoscopy for a single primary SCCHN at the University Hospital CHUV, Lausanne, Switzerland. One hundred and seventeen biopsies were taken during this endoscopy. Three quarters of the biopsies of histologically normal squamous cell mucosa came from esophagus and the rest from the buccal mucosa. In $90 \%$ of the cases, the biopsy was cut in two pieces. One half was sent for conventional histological examination and the second half was used for assessing p53 mutation events. All samples of normal tissue were taken at least $10 \mathrm{~cm}$ away from the primary tumor, and the distance between individual biopsies was at least $2 \mathrm{~cm}$. Samples for functional testing were placed directly in RNA lysis buffer and immediately frozen on dry ice, and stored at $-80^{\circ} \mathrm{C}$ until use. Procedure of identification of p53 mutations by yeast functional assay has been described earlier $[9,10]$.

The data collected included age, gender, primary tumor site (oral cavity, pharynx, larynx, esophagus, rhinopharynx), tumor size $\left(\mathrm{T}_{1-4}\right)$, lymph node status $\left(\mathrm{N}_{0-3}\right)$, staging according to the American Joint Committee on Cancer Stage (stages I-IV), initial therapy (surgery only, radiationtherapy with or without concomitant chemotherapy, surgery with radiation-therapy with or without concomitant chemotherapy, palliative treatment), and cause of death. During the follow-up, recurrences and non-sterilization of primary tumor, occurrence of lymph node metastases, and of second primary tumors (SPT) were recorded.

Statistical analysis: major endpoints of this study were local relapse, second primary tumors (SPT), lymph node metastases, and death during the follow-up, in relation to the p53 mutation status in tumor-distant mucosae. Calculations were performed using Fisher's exact test for univariate analysis and $P<0.05$ was considered as significant. The Kaplan-Meier method and log-rank test were used to compare overall and disease-related survival curves between groups with p53 wild type and mutated type. Statistical analyses were done using the package Survival from the R Project for statistical Computing (http://www.r-project.org/) $[11,12]$.

\section{Results}

Thirty-five patients with a single primary SCCHN were included in this study. One patient from the previous study was excluded because of loss to follow-up directly after diagnostic broncho-esophagoscopy. The p53 status in the 
tumor distant mucosae of the 35 patients and their main clinical characteristics are summarized in Table 1. Sixteen out of $35(45.7 \%)$ patients showed p53 mutations in at least one biopsy of normal tissue, and 19 out of 35 (54.3\%) patients showed no p53 mutation. There was no statistically significant difference between the two groups concerning age, gender, primary tumor site, stage, and initial treatment. The follow-up period ranged from less than 1 month to 131 months (10.9 years), with a mean period of 54 months for the group with p53 mutation, 57 months for the group without mutations. A total of 21 patients died during the followup period. No relationship was found between overall survival and p53 mutation status $(P=0.213)$. Five patients in

Table 1 Distribution of patients according to p53 status in histologically normal mucosa

\begin{tabular}{|c|c|c|c|}
\hline & $\begin{array}{l}\text { p53 } \\
\text { Mutated }\end{array}$ & $\begin{array}{l}\text { p53 Not } \\
\text { mutated }\end{array}$ & $P$ \\
\hline Overall & 16 & 19 & \\
\hline Age & & & 0.26 \\
\hline$>65$ & 14 & 13 & \\
\hline$\leq 65$ & 2 & 6 & \\
\hline Gender & & & 0.24 \\
\hline Female & 2 & 6 & \\
\hline Male & 14 & 13 & \\
\hline \multicolumn{4}{|l|}{ Anatomic site } \\
\hline Oral cavity & 3 & 5 & \\
\hline Pharynx & 8 & 9 & \\
\hline Larynx & 2 & 4 & \\
\hline Esophagus & 2 & 1 & \\
\hline Rhinopharynx & 1 & 0 & \\
\hline Staging & & & 0.85 \\
\hline Stage I & 1 & 1 & \\
\hline Stage II & 2 & 4 & \\
\hline Stage III & 3 & 5 & \\
\hline Stage IV & 10 & 9 & \\
\hline Tumor size & & & 0.54 \\
\hline $\mathrm{T}_{1}$ & 2 & 2 & \\
\hline $\mathrm{T}_{2}$ & 2 & 6 & \\
\hline $\mathrm{T}_{3}$ & 6 & 7 & \\
\hline $\mathrm{T}_{4}$ & 6 & 4 & \\
\hline Lymph node & & & 0.35 \\
\hline $\mathrm{N}_{0}$ & 6 & 10 & \\
\hline $\mathrm{N}_{1-3}$ & 10 & 9 & \\
\hline \multicolumn{4}{|l|}{ Initial therapy } \\
\hline Surgery & 4 & 8 & \\
\hline $\begin{array}{l}\text { Surgery + radiation } \pm \\
\text { chemotherapy }\end{array}$ & 4 & 3 & \\
\hline Radiation \pm chemotherapy & 6 & 5 & \\
\hline Palliative therapy & 2 & 3 & \\
\hline
\end{tabular}

$P$ values from univariate analysis with $P<0.05$ considered significant each group died of tumor-related events. Disease-specific survival did not significantly differ between the two groups $(P=0.914)$. There was no association between disease-free survival and the p53 mutation status $(P=0.439)$. The rate of SPT was not associated with p53 mutation status in samples of normal mucosa $(P=1)$ (Table 2). In the group without p53 mutation, 2 of $19(10.5 \%)$ patients developed a SPT: one patient who presented with a primary retromolar space tumor developed an SPT on the floor of the mouth after 24 months; the other patient presented with a pulmonary carcinoma 21 months after the treatment of a primary squamous cell carcinoma of the esophagus. Two of 16 $(12.5 \%)$ patients with p53 mutation developed bronchogenic carcinomas as SPT; one patient 97 months after the treatment of a primary tongue base tumor and the other patient 14 months after the treatment of a primary tumor situated on the border of the tongue. There was no statistically significant difference between the two groups in the incidence of loco-regional recurrence or progression $(P=1)$.

\section{Discussion}

Mutations leading to inactivation of the p53 tumor suppressor gene are a frequent event in the pathogenesis of head and neck tumors. Genetic analysis of histologically normal samples of mucosae revealing the presence of multiple clones of mutant p53-containing cells has formed the basis for a molecular understanding of the field cancerization process [10]. According to this observation, we postulated that the p53 status of normal squamous cell mucosae samples might be relevant for predicting the clinical outcome of head and neck patients and could be used as a biomarker to predict a multifocal pattern of disease, thus facilitating identification of patients at high risk of developing SPT.

To assess the clinical value of p53 mutations in normal tissue, we used a functional assay testing the transcriptional competence of human p53 expressed in yeast. The results were compared with the long-term follow-up of the patients.

Table 2 Outcome of patients according to p53 status in histologically normal mucosa

\begin{tabular}{lll}
\hline & $\begin{array}{l}\text { p53 } \\
\text { Mutated }\end{array}$ & $\begin{array}{l}\mathrm{p53} \\
\text { Not mutated }\end{array}$ \\
\hline Events during follow-up & & \\
Deaths; overall & 13 & 8 \\
Deaths; tumor-related & 5 & 5 \\
SPT & 2 & 2 \\
Loco-regional & 5 & 5 \\
recurrence/progression & & \\
\hline
\end{tabular}


The incidence of p53 mutation in our study was $45.7 \%$. In the literature, this incidence varies from $47 \%$ to less than 5\% [13-15], whereas in several other studies, no p53 mutations were found in normal tissue [16-18]. These variations in incidence of p53 mutation could partially be explained by the heterogeneity of the different studies, in terms of the techniques used for assessing p53 mutations, and of the localization of tumors.

This study did not demonstrate any relationship between the p53 mutations of histologically normal tissues distant from the primary tumors and the clinical outcome. Although p53 mutations were associated with a slight decrease in disease-free and overall survival - the number of overall deaths was 13 in the group with p53 mutations versus eight patients in the group without p53 mutationthis difference was not statistically significant. This lack of statistical power may be due to the low number of cases in our study. Especially, the occurrence of SPT was almost identical in both groups. In each group, two patients presented with a SPT, and three of them were located in the lungs. Consequently, p53 mutations in histologically normal tissue do not seem to be a reliable prognostic factor of the clinical outcome of patients.

Homann et al. [15] analyzed the clinical outcome of head and neck cancer patients in relationship to $\mathrm{p} 53$ protein overexpression assessed by immunohistochemistry in tumor-distant epithelia. Their results showed no significant correlation between mucosal p53 overexpression and disease-free and overall survival. Contrary to our own results, their series showed a statistically significant association between p53 overexpression in normal mucosa and the incidence of SPT. A possible explanation for these contradictory results might be the different mutation detection techniques used in these two series. Even if immunohistochemical detection of the $\mathrm{p} 53$ protein is widely used as a marker of p53 gene mutation, this technique leads to discordant results in up to $40 \%$ of the cases [19, 20]. Furthermore, correlation between p53 mutations and overexpression has been found to be low in tumor-distant mucosa. The method of yeast p53 functional analysis that we used allows the screening of the p53 gene (codons 52-364) with a high sensitivity and specificity, but it seems clear from our results that more complete analysis of the genetic changes in preneoplastic cells will be needed to identify useful prognostic biomarkers in SCCHN. Carcinogenesis is a complex phenomenon with multiple genetic lesions and gene product interactions, so it is not surprising that a single molecular marker cannot predict the prognosis accurately [21]. Indeed, since performing our initial study microarray techniques have been developed that permit testing of the entire genome in a single assay. Use of these techniques would provide a much more comprehensive view of the extent of genetic damage to the normal mucosa.
Another reason for the lack of correlation between p53 mutations in tumor-distant mucosa and the development of SPT in our series might be the small number of cases, especially when considering that SPTs are far more likely to develop in patients initially presenting with earlier stages of disease. The ability to identify patients at increased risk of developing multifocal disease is most important in patients with small primary tumors $\left(\mathrm{T}_{1}\right.$ and $\mathrm{T}_{2}$ cancers), because more than $80 \%$ of SPTs are small superficial tumors (in situ or $\mathrm{T}_{1}$ ) which are amenable to non-mutilating surgery $[5,6]$. The statistical power of our series was probably diminished by this property of SCCHN, because more than half of the patients presented with advanced stages of the disease (III and IV). Although this study failed to demonstrate any benefit from the screening of p53 mutations in normal squamous cell mucosae of head and neck cancer patients, p53 mutations might be predictive of SPT and of disease-specific survival in a population presenting with earlier stages of the disease. Further studies are needed to confirm this hypothesis.

\section{Conclusion}

Contrary to our initial assumption, this study did not show any correlation between p53 mutations in histologically normal squamous cell mucosa of the head and neck and the incidence of SPT. The latter is generally low and the benefit of analyzing p53 mutations in tumor-distant mucosae in every patient presenting with a primary head and neck cancer is doubtful. It is possible that other markers might improve the clinical value of p53 status and so facilitate identification of those patients who are at high risk of developing metachronous second primary tumors.

\section{References}

1. Jemal A, Murray T, Ward E, Samuels A, Tiwari RC, Ghafoor A, Feuer EJ, Thun MJ (2005) Cancer statistics, 2005. CA Cancer J Clin 55:10-30

2. Leon X, Quer M, Diez S, Orus C, Lopez-Pousa A, Burgues J (1999) Second neoplasm in patients with head and neck cancer. Head Neck 21:204-210

3. Khuri FR, Kim ES, Lee JJ, Winn RJ, Brenner SE, Lippman SM, Fu KK, Cooper JS, Vokes EE, Chamberlain RM, Williams B, Pajak TF, Goepfert H, Hong WK (2001) The impact of smoking status, disease stage, and index tumor site on second primary tumor incidence and tumor recurrence in the head and neck retinoid chemoprevention trial. Cancer Epidemiol Biomarkers Prev 10:823829

4. Slaughter DP, Southwick HW, Sejkal W (1953) Field cancerization in oral stratified squamous epithelium, clinical implication of multicentric origin. Cancer 6:963-968

5. Vokes EE, Weichselbaum RR, Lippman SM, Hong WK (1993) Head and neck cancer. N Engl J Med 328:184-194 
6. Savary M, Monnier P, Pasche R, Brossard E, Pasche P, Lang F (1991) Multiple primary malignancies. Adv Otorhinolaryngol 46:165-175

7. Field JK (1995) The role of oncogenes and tumour-suppressor genes in the aetilogy of oral, head and neck squamous cell carcinoma. J R Soc Med 88:35-39

8. Harris CC, Hollstein M (1993) Clinical implcations of the p 53 tumor suppressor-gene. N Engl J Med 329:1318-1327

9. Waridel F, Iggo R (1996) Identification of clonal mutations in morphologically normal mucosa of the aero-digestive tract. Eur $\mathbf{J}$ Cancer Prev 5(Suppl 2):67-73

10. Waridel F, Estreicher A, Bron L, Flaman J-M, Fontolliet C, Monnier P, Frebourg T, Iggo R (1997) Field cancerisation and polyclonal p53 mutation in the upper aero-digestive tract. Oncogene 14:163-169

11. Harrington DP, Fleming TR (1982) A class of rank test procedures for censored survival data. Biometrika 69:553-566

12. Ikhaka R, Gentleman RR (1996) A language for data analysis and graphics. J Comput Graph Stat 5:299-314

13. Tabor MP, Brakenhoff RH, van Houten VM, Kummer JA, Snnel MH, Snijders PJ, Snow GB, Leemans CR, Braakhuis BJ (2001) Persistence of genetically altered fields in head and neck cancer patients: biological and clinical implications. Clin Cancer Res 7:1523-1532

14. Homann N, Nees M, Conradt C, Dietz A, Weidauer H, Maier H, Bosch FX (2001) Overexpression of p53 in tumor-distant epithelia of head and neck cancer patients is associated with an increased incidence of second primary carcinoma. Clin Cancer Res 7:290296

15. Partridge M, Li SR, Pateromichelakis S, Francis R, Phillips E, Huang XH, Tesfa-Selase F, Langdon JD (2000) Detection of minimal residual cancer to investigate why oral tumors recur despite seemingly adequate treatment. Clin Cancer Res 6:2718-2725

16. Sasano H, Miyazaki S, Gooukon Y, Nishihira T, Sawai T, Nagura $\mathrm{H}$ (1992) Expression of p53 in human esophaeal carcinoma: an immunohistochemical study with correlation to proliferating cell nuclear antigen expression. Hum Pathol 23:1238-1243

17. El-Naggar AK, Lai S, Luna MA, Zhou XD, Weber RS, Goepfert H, Batsakis JG (1995) Sequential p53 mutation analysis of preinvasive and invasive head and neck squamous carcinoma. Int $\mathrm{J}$ Cancer 64:196-201

18. Gonzalez-Moles MA, Galindo P, Gutierrez J, Rodriguez-Archilla A, Ruiz-Avila I, Sanchez-Fernandez E (2002) Significance of p53 expression in non-tumoral epithelium adjacent to oral suaqmous cell carcinomas. J Laryngol Otol 116:355-358

19. Taylor D, Koch WM, Zahurak M, Shah K, Sidransky D, Westra WH (1999) Immunohistochemical detection of p53 protein accumulation in head and neck cancer: correlation with p53 gene alterations. Hum Pathol 30:1221-1225

20. Ma L, Ronai A, Riede UN, Kohler G (1998) Clinical implication of screening p53 gene mutations in head and neck squamous cell carcinomas. J Cancer Res Clin Oncol 124:389-396

21. Roth JA (1999) p53 prognostication: paradigm or paradox? Clin Cancer Res 5:3345 